\title{
Effects of Loading Conditions on Hydrodynamics of a Hard-Chine Planing Vessel Using CFD and a Dynamic Model
}

\author{
Hamid Kazemi ${ }^{1}$, Mahmoud Salari ${ }^{2 *}$ \\ ${ }^{1}$ Ph.D Student, Imam Hosein Univ.; Marine Research Center, stableboat.90@hotmail.com \\ ${ }^{2}$ Associate Prof., Imam Hosein Univ.; Marine Research Center, msalari@ihu.ac.ir
}

\section{ARTICLE INFO}

Article History:

Received: 4 Dec. 2016

Accepted: 15 Mar. 2017

Keywords:

Hydrodynamics

Computational Fluid Dynamic

Planing Vessel

Moving Mesh Technique

Loading Conditions

\begin{abstract}
Planing vessels usually have low ratios of resistance to weight, so they can move fast on sea surface than the displacement or semi-displacement ships. Access to higher speeds is one of the attractions for designers and users. To achieve higher speeds, reducing the hydrodynamic resistance is a necessity for this class of vessels. In this study, a 3D finite volume approach is used to analyze the hydrodynamics of the Cougar high-speed vessel, a hard chine planing hull. In addition to use of the URANS equations for momentum, SIMPLE algorithm for coupling of the pressure and velocity field and the k- $\varepsilon$ for turbulence modeling, the fluid phases of air/water and the free surface are modeled using the volume of fraction (VOF) scheme. Moreover, in the simulations, instead fixing the freedom of the model regards to the computational domain, the vessel motions are also considered to have two degrees of freedom, 2-DOF, using the newly developed moving mesh technique of Overset. The grid independency study shows a good consistency between the numerical results and experiments for the vessel resistance, trim angles and the heave. Main emphasis of this paper is on study of the effects of different loading conditions, the vessel weight and the longitudinal center of gravity, on the hydrodynamic characteristics such as resistance, trim angle and the vessel sinkage. All of the numerical simulations are done using the commercial software of Star CCM+
\end{abstract}

\section{Introduction}

High-speed planing vessels are used extensively in both of the civil and military applications, so demands for improvement of these vessels are also increased. Moreover, design of these vessels and their relevant analysis has significant importance because their motion characteristics are very sensitive to loading conditions. Increase in the ratio of velocity to engine power, as an interested parameter for users, is directly depended on their hull form and their relevant loading conditions. When a planing hull moves in its cruise speed, the hydrodynamic lift force created by their bottom planing surfaces would be enough to lift 50 to 90 percent of the vessel weight. The hydrodynamic lift force produced by planing surfaces is one of the main reasons for reducing the vessel sinkage and increasing their speeds (Doctors LJ (1985)). The increase in speed will be accompanied by a change in the dynamic trim angle and a decrease in hydrodynamic resistance. Savitsky et al. (2010) reported that for a planing vessel the lowest ratio of resistance to hydrodynamic lift would be occurred for a trim angle of approximately 4 degrees. In conventional planing hulls, the increase in speed leads to a reduction in their trim angle, and as a result, the vessel behavior will proceed to a non-optimal mode. The use of hull forms having transverse step on their bottom surface has been considered as a solution to address this problem (Savitsky et al. (2010)). Hydrodynamics of high-speed planing vessels can be investigated using the model tests, analytical or semiempirical methods (regression formula) and computational fluid dynamic, CFD, approaches. The model tests are usually expensive and time consuming. The analytical and semi-empirical methods are also applicable to simple prismatic hulls, only. The newer planing vessels usually utilized from complex geometries so that a necessity for a highly efficient analysis method emerged. In recent years, the computational fluid dynamic methods play as a powerful tool for analyzing of such issues. Employing the CFD tool alongside model tests has reduced number of model tests (Lotfi et al. (2015)). 
Studies on the hydrodynamic of the planing vessels have a long history. A wide range of model tests on systematic series (Series 62 Model) of planing vessels were done by Clement et al. (1963). Today, the model and obtained results of Clement (1963) is used for calibrating of newly constructed towing tanks. In a recent study done by Seo et al. (2016), the resistance and seakeeping performance of a high-speed monohull vessel with slender wave-piercing bow, round bilge, and small deadrise angle were investigated through a series of model tests with and without spray-rails in a towing tank. They reported that the spray rails did not have any negative effects on the resistance performance of the hull, while they effectively stabilized the vessel in calm water and waves. Many details about the research in the field of planing vessels can be found in the reference of Faltinsen, (2006). Studies on numerical simulation of high-speed vessels using computational fluid dynamic is extended to the recent decades. As one of the first studies in this field, Caponnetto (2001) employed RANS solver for the hydrodynamic analysis of highspeed vessels. He utilized an interpolation technique for obtaining the final moving state of the vessel from the numerical simulations. Ghassemi and Su (2008) used a combination of potential-based boundaryelement method and the viscous boundary layer theory to determine hydrodynamic forces on a planing hull in steady motion. Brizzolara and Serra (2007) performed a research on numerical analysis of planing plate in fixed position and compared the achieved results with model test results of Savitsky (1964) and Shuford (1958). An error of about 15 percent reported in their study indicated the potential of computational fluid dynamics to address the mentioned problem.

Panahi et. al. (2009) proposed a numerical simulation algorithm based on the finite volume discretization for analyzing boat motions. The proposed method employed a fractional step method to deal with the coupling between the pressure and velocity fields.

Savitsky and Morabito (2010) studied experimentally the free-surface wake patterns after the transom of prismatic planing hulls. In addition, they provided empirical formulas for quantitative definition of wake pattern in center-line and in $(1 / 4 \mathrm{~B})$ distance of the center-line of the vessel. Their experimental results helped investigators to validate their numerical results. Hay et al. (2006) presented a research on Navier-Stokes simulations of multiphase flows around moving bodies coupled with an adaptive mesh refinement strategy. Su et al. (2012) presented a new CFD method to calculate hydrodynamic forces of planing vessels. The numerical method was based on Reynolds-Averaged Navier-Stokes (RANS) equations; the volume of fluid (VOF) method and the six-degrees-of-freedom equation. Yousefi et. al (2013) have reviewed and analyzed different techniques that have been used over recent decades for hydrodynamic prediction of high speed planing hulls.

Ghadimi et al. (2014) developed a computer program based on Morabito's approach. Taunton et al. (2010) conducted laboratory studies on new series of hardchine planing hulls and analyzed their study in calm water and wave conditions. Wang at al. (2012) presents a study on the numerical simulation of planing crafts sailing in regular head, oblique and beam waves in three different velocities. The simulation set in six-degree of freedom motions are based on the Reynolds averaged Navier Stokes equations volume of fluid (RANSE VOF) solver. Sukas et.al (2017) evaluated the opportunity of utilizing the overset grid system to solve the fluid flow around planing hulls. They concluded that the overset grid can captures, in a good manner, the large motions of these vessels at high Froude numbers.

It can be seen several numerical simulations of planing vessel using CFD have been carried out, but in most cases the model has been kept statically and a steady state simulation has been performed. The existence of the free surface, multi-phase issue alongside the dynamic meshing of their complex geometries are some of the difficulties for investigators who are engaged with fluid flow analysis of moving planing vessels.

In this paper, the unsteady Reynolds-averaged NavierStokes, URANS, equations are solved to achieve unsteady dynamic motions of a mono-hull planing vessel of Cougar type. Some experiments are done for the model in a laboratory where obtained data are used for validating of the numerical results. Then in order to study the effects of loading conditions, weight and longitudinal center of gravity, on the dynamics and hydrodynamics of the vessel in different speeds, numerical simulations are done for 18 different loading and speed states.

\section{Model Geometry}

In this study, simplified form of Cougar vessel is selected as the test model. Main dimensions and other characteristics of this model are presented in table 1 . The 3D model and body lines of this vessel are depicted in Figure1 and Figure 2.

Table1. Main dimensions and characteristics of model

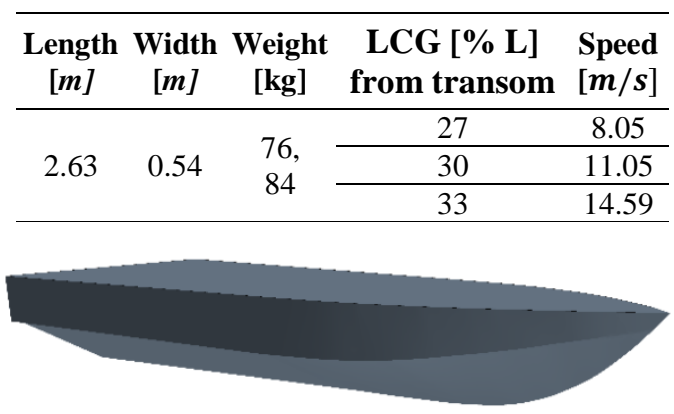

Figure 1. CAD model of the Cougar hull 


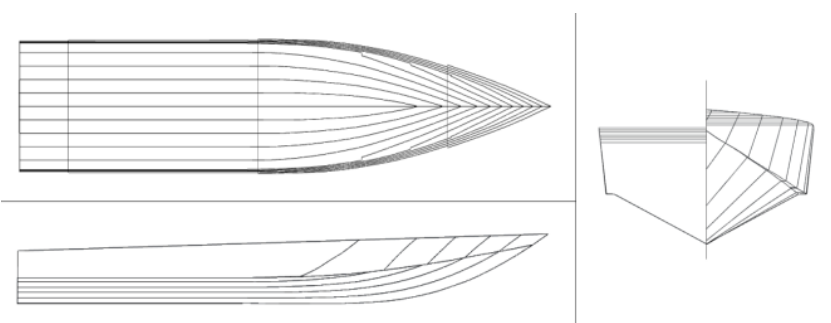

Figure 2. The Cougar body lines

\section{Model tests and results}

Since there was not any validated data for this hardchine planing vessel in the literature and the model were different from classical planing prismatic models, the authors planned to get some experimental data for this model.

The experimental data is used to validate the numerical results. The model tests of Cougar vessel model is accomplished in the National Iranian Marine Laboratory (NIMALA) towing tank. This towing tank is constructed in 2012. It has a length, width and depth of 400, 6 and 4 meters, respectively. The Clement data tests (on series 62 model) have been used for calibrating of measurements of this newly constructed towing tank.

The experiments on the model have been done in three loading conditions and different speeds. Experimental results are shown in Table 2. Figure 3 shows some photo shots during the test.

Table2. Conditions and results of the towing tank tests

\begin{tabular}{|c|c|c|c|c|c|c|c|}
\hline $\begin{array}{l}\text { Test } \\
\text { No. }\end{array}$ & $\begin{array}{c}\text { Weight } \\
{[\mathrm{kg}]}\end{array}$ & $\begin{array}{c}\text { LCG } \\
{[m]}\end{array}$ & $\begin{array}{l}\text { Speed } \\
{[\mathrm{m} / \mathrm{s}]}\end{array}$ & $\begin{array}{c}\text { Resistance } \\
{[N]}\end{array}$ & $\begin{array}{l}\text { Trim } \\
\text { [deg.] }\end{array}$ & $\begin{array}{l}\text { Static } \\
\text { Trim } \\
\text { Angle } \\
{[\text { deg. }]}\end{array}$ & $\begin{array}{l}\text { Initial } \\
\text { Draught } \\
{[\mathrm{m}]}\end{array}$ \\
\hline 1 & 57.36 & 0.922 & 8.05 & 121.2 & 2.34 & 0.17 & 0.118 \\
\hline 2 & 93.16 & 0.988 & 11.05 & 230.8 & 2.2 & 0.34 & 0.153 \\
\hline 3 & 108.6 & 1.125 & 11.50 & 256.9 & 1.99 & 0.21 & 0.168 \\
\hline
\end{tabular}
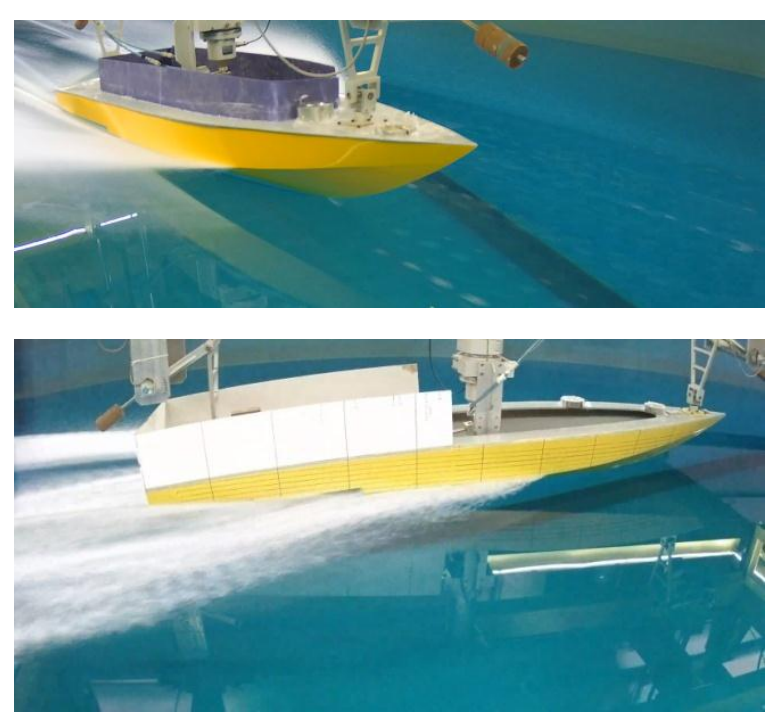

Figure 3. Cougar Model in NIMALA towing tank

\section{Numerical study}

Unsteady dynamics of a hard-chine planing vessel confined to have only two-degrees of freedom of heave and pitch at different loading conditions and different speeds are simulated using the commercial software of Star CCM+. The simulations are based on using the finite volume approach.

\subsection{The equations of fluid flow}

The fluid flow simulations are based on solutions of the unsteady Reynolds averaged Navier-Stokes, URANS, equations, the $k-\varepsilon$ turbulent model equations and using the SIMPLE algorithm for coupling the pressure and velocity fields. Moreover the volume of fraction, VOF, scheme is used for consideration of both phases of water/air and their interfaces. The URANS and continuity equations are as below:

$$
\begin{aligned}
& \frac{\partial \bar{u}_{i}}{\partial x_{i}}=0 \\
& \frac{\partial\left(\bar{u}_{\imath}\right)}{\partial t}+\bar{u}_{J} \frac{\partial\left(\bar{u}_{\imath}\right)}{\partial x_{j}}=-\frac{1}{\rho} \frac{\partial \bar{P}}{\partial x_{j}}+g_{i}+\frac{\mu}{\rho} \nabla^{2} \bar{u}_{i}-\frac{1}{\rho} \frac{\partial \tau_{i j}}{\partial x_{j}}
\end{aligned}
$$

where $\mathrm{g}_{\mathrm{i}}$ is a gravity acceleration component, $\rho, \mu$, $\tau_{\mathrm{ij}}=\overline{\mathrm{u}}_{\mathrm{i}} \mathrm{u}_{\mathrm{j}}$ are density, dynamic viscosity of the fluid and Reynolds stress tensor respectively. The Reynolds stress tensor is modeled using the $\mathrm{k}-\varepsilon$ turbulence model.

\subsection{Turbulence modeling}

For modeling the flow turbulence around the body of the vessel, $\mathrm{k}-\varepsilon$ turbulence model which is one of the most applicable turbulence models in aerodynamic and hydrodynamic issues, was utilized. In this model, an eddy viscosity is defined for computing the Reynolds stresses based on the analogy of laminar flows for the relation between the shear stress, fluid viscosity and velocity gradient.

$$
\mu_{t}=C_{\mu} \frac{\rho k^{2}}{\varepsilon}
$$

Where $\mathrm{k}$ is the turbulence kinetic energy per unit mass and $\varepsilon$ is the dissipation rate of the turbulence kinetic energy per unit mass. The $C_{\mu}$ is a constant equals to 0.09 . The $\mathrm{k}$ and $\varepsilon$ are computed locally from the transport equations of (4) and (5) (Ferziger et al. (2002)).

$$
\begin{array}{r}
\frac{\partial \rho k}{\partial t}+\nabla \cdot(\rho \bar{U} k)=\nabla \cdot\left[\left(\mu+\frac{\mu_{t}}{\sigma_{k}}\right) \nabla k\right]+P_{k}-\rho \varepsilon \\
\frac{\partial \rho \varepsilon}{\partial t}+\nabla \cdot(\rho \bar{U} \varepsilon)=\nabla \cdot\left[\left(\mu+\frac{\mu_{t}}{\sigma_{k}}\right) \nabla \varepsilon\right]+\frac{\varepsilon}{k}\left(C_{z 1} P_{k}-C_{z 2} \rho \varepsilon\right)
\end{array}
$$

where $\mathrm{P}_{\mathrm{k}}$ is the production term and defined as follow:

$$
\begin{gathered}
P_{k}=\mu_{t} \nabla \bar{U} \cdot\left(\nabla \bar{U}+\nabla \bar{U}^{T}\right)-\frac{2}{3} \nabla \cdot \bar{U}\left[3 \mu_{t} \nabla \cdot \bar{U}\right. \\
+\rho k)]
\end{gathered}
$$




\subsection{Coupling the Dynamics and Hydrodynamics}

In order to simulate the dynamic behavior of the vessel, fluid-structure interaction between body structure and fluid is considered. This problem is addressed by solving the solid body motions of the vessel confined in two-degrees of freedom in the heave and pitch axes. The relevant algorithm is shown in Figure 4.

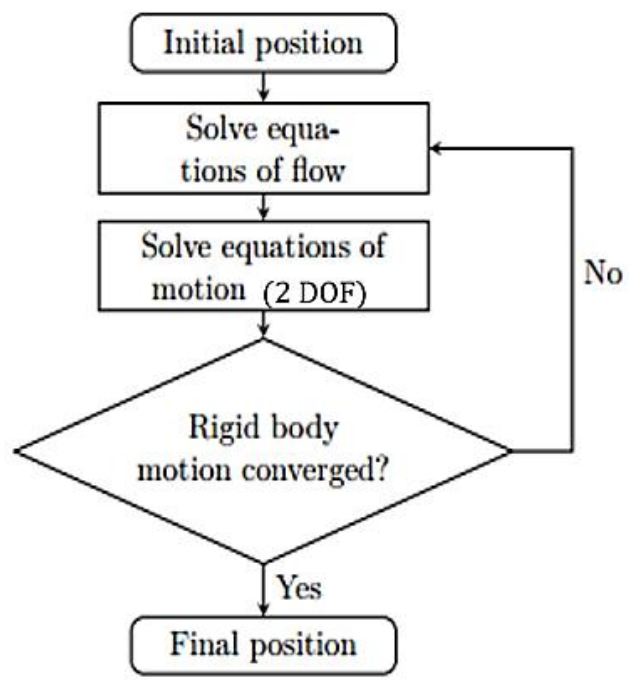

Figure 4. Computational algorithm for the simulations

As it can be seen in Figure 4, the initial characteristics of model are defined for the model. This includes model positions, initial speed of the model and its initial trim angle. Then the fluid flow equations are solved and a set of results are obtained. Based on the fluid flow results, the hydrodynamic forces are also calculated. For the next stage, the solid body dynamic equations are solved and the new position parameters of the model are obtained. If the new position parameters such as the trim angle and draught didn't changed respect to their values at former time step, the solution is finished. Elsewhere the solution process is continued. In most cases of the simulations, the final state of the moving vessel with a constant speed tended to a steady state. While in some cases of loading conditions or at some moving speeds, the final state of the vessel, in the heave or pitch directions, was not kept constant and their values changed harmonically. This type of instability usually occurs for actual planing boats in calm water and named as the "proposing instability".

\subsection{Computational Domain}

The computational domain is determined in a way that the effects of the boundaries on the solutions would be minimized. The non-dimensional distances between the body and the side surfaces of the rectangular cuboid of the computational domain are shown in Figure 5.

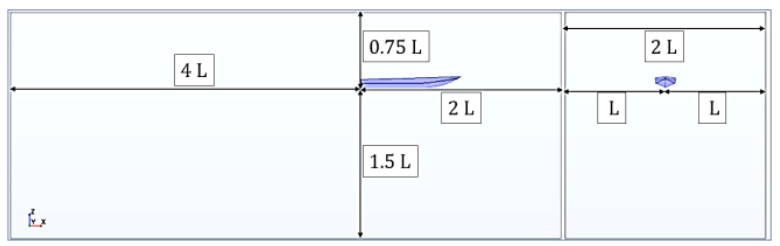

Figure 5. Main dimension of computational domain

\subsection{Boundary conditions}

As shown in Figure 6, boundary conditions are applied as follow:

a) For the right, up and down boundaries of the domain, a flow with a constant and uniform velocity is applied.

b) For the side boundaries, left and right surfaces, a symmetry condition with hydrostatic pressure distribution is defined.

c) Body surfaces of the model are defined as an impermeable and non-slip wall.

d) For the outlet surface, downstream, a pressure outlet condition is applied.

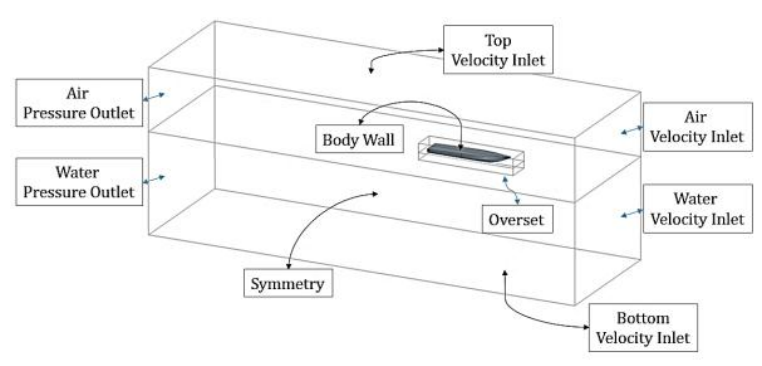

Figure 6. The boundary conditions of simulation

\subsection{Mesh Generation}

The computational domain is discretized into finite volumes using a structured meshing. The size of mesh is finer in various regions such as near the body walls, around the water free surface, the region behind the vessel and around the hard chines. In order to model a dynamic vessel the Overset technique is employed. This method takes the advantage of two overlapping meshes, one for moving part and the other for fixed part of the background. In order to move the body, the moving part which is known as Overset uses the displacement and rotation method. All cells retain their shape and mesh movement is described using displacement vector and rotation angles. These two meshes are connected through the interfaces. Parametric values of pressure and flow velocity are calculated using interpolation of the two mesh interfaces. To introduce this method more detailed, the mesh created around a simple square and is depicted in Figure 7. Meshes for whole of the computational domain can be observed in Figure 8. 


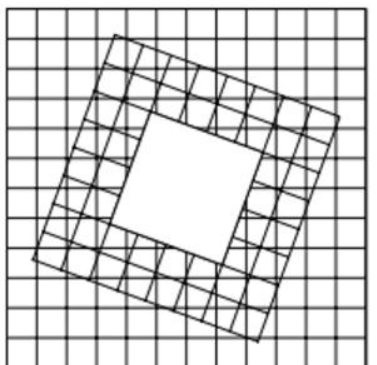

Figure 7. Overset meshing technique around a square
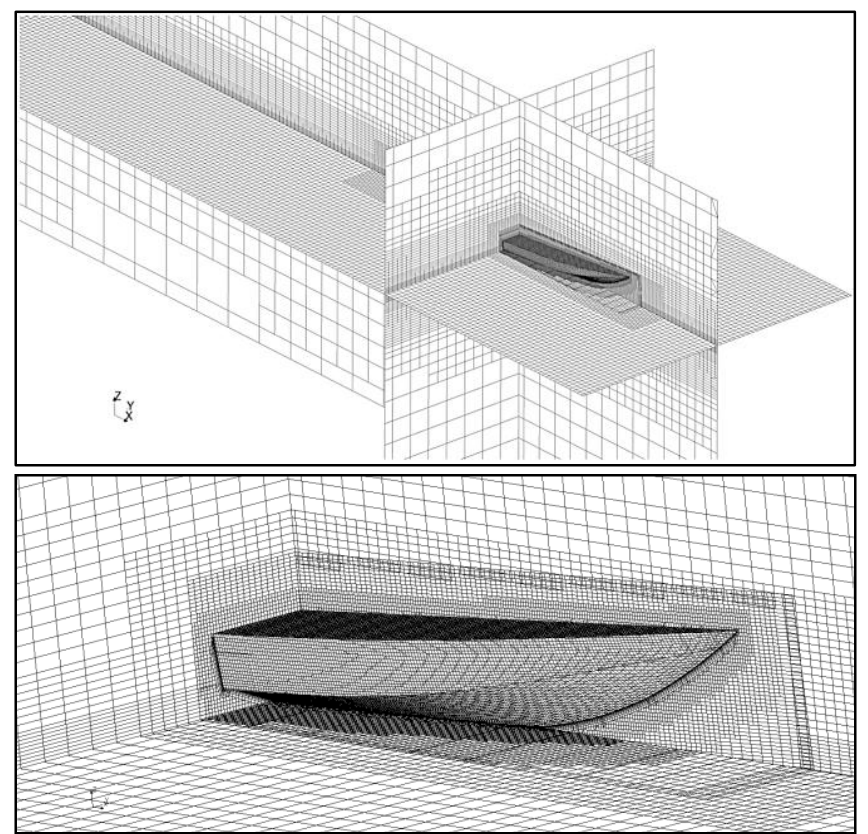

Figure 8. Meshing of the computational domain using trimmer method

For turbulent boundary layers, which occurs on more regions of the wetted area of the vessel, the height of the first cells near the vessel surface has an important role on the computed results. To evaluate the quality of mesh within the boundary layers, non-dimensional parameter $y^{+}$is examined as an important criterion. This parameter refers to the non-dimensional distance of the first knot of the mesh from the surface. The value of this parameter is calculated using formula (7):

$$
y^{+}=\frac{\rho u_{\tau} \Delta y}{\mu}
$$

Where $\Delta y$ is the distance between wall and the first knot of the mesh and $u_{\tau}$ is the friction velocity. For a turbulent boundary layer, followed by using an eddy viscosity turbulence model like the $\mathrm{k}$-e, the recommended value of $y^{+}$is between 50 and 150. In Figure 9, distribution of $y^{+}$on the body of the vessel is depicted in which it is observed that the mean value of this parameter is 80 .

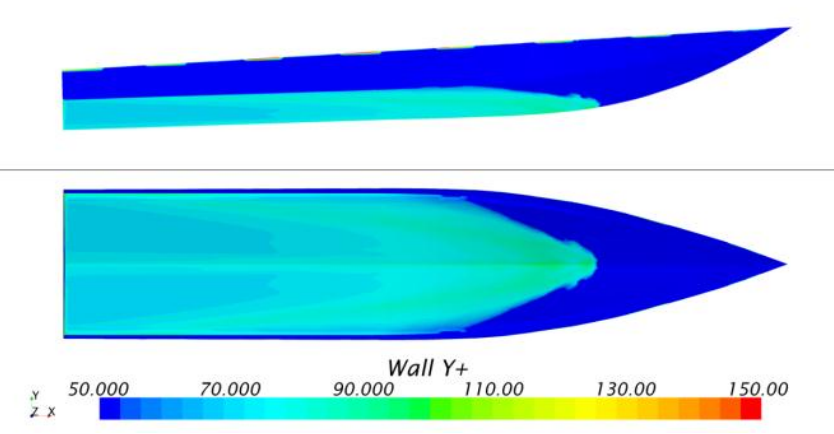

Figure 9. The $y^{+}$variations on body surface of the vessel

\subsection{Mesh independency study}

Another issue in numerical simulations is making use of a mesh in which the results obtained are independent of number and the measure of the elements. To ensure this, three different grids; 1) a coarse mesh with 922,000 elements 2) a medium mesh with 988,000 elements and 3) a fine mesh with $1,125,000$ elements, are created and the simulation for the vessel at the speed of $11.502 \mathrm{~m} / \mathrm{s}$ is carried out. The relevant values of hydrodynamic resistance, trim and draft are displayed in Figure 10 for different meshes.

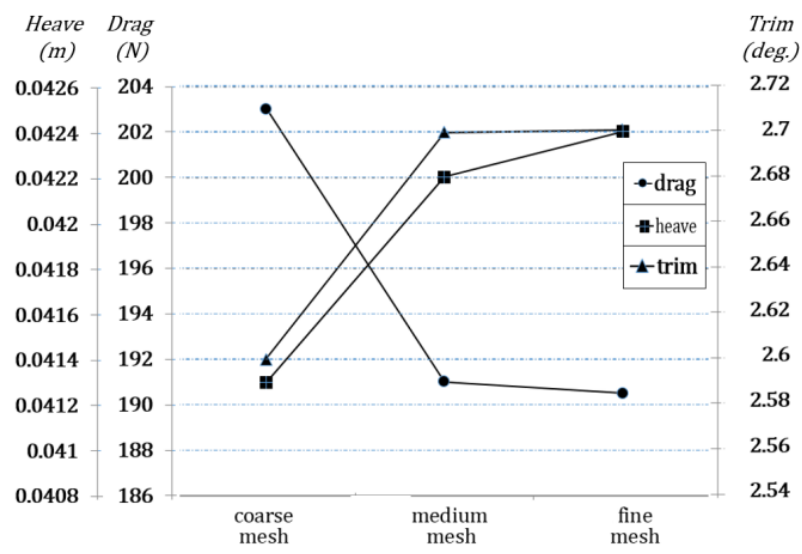

Figure 10. Convergence of the results in mesh independency study

These simulations were carried out on a processor (Intel Core i7, $3.4 \mathrm{GHz} \mathrm{CPU}$ ), with 16 Gigabyte of RAM. The time step value was considered as 0.0005 . The average of 6000 time steps equivalent to 30000 iterations for each simulation was needed. This time is proportional to the abiding time of the vessel's movement. Also the value of residuals should be lower than $1 \cdot 10^{-3}$. For a medium-density mesh, computation time was about 120 hours approximately. According to Figure 10 and also time consuming simulations, the medium-density mesh was considered for future simulations.

\subsection{Validation}

To verify and validate simulation results, Table 3 shows the drag and trim results of the vessel in three 
different states, for both experimental and numerical methods.

Table 3.Comparison of numerical and laboratory results for validating of numerical simulations

\begin{tabular}{|c|c|c|c|c|c|}
\hline \multirow{2}{*}{$\begin{array}{c}\text { Test No. } \\
\text { (Conditions } \\
\text { same as Table 1) }\end{array}$} & \multicolumn{3}{|c|}{ Resistance (N) } & \multicolumn{2}{|c|}{ Trim (deg.) } \\
\hline & Lab. & Num. & $\begin{array}{c}\text { Deviation } \\
\%\end{array}$ & Lab. & Num. \\
\hline 1 & 121.2 & 127 & 4.8 & 2.34 & 2.58 \\
\hline 2 & 230.8 & 233 & 0.9 & 2.2 & 2.6 \\
\hline 3 & 256.9 & 269.2 & 4.7 & 1.99 & 2.58 \\
\hline
\end{tabular}

It can be seen the maximum deviation between the numerical and experimental results for the drag is below $5 \%$ which shows a good consistency.

\section{Loading Conditions Effects}

In order to study the effects of the weight and longitudinal center of gravity on the dynamic behavior and resistance in different speeds, the vessel is simulated in 18 different loading and speed states. These simulations are carried out considering two weights of 76 and $84 \mathrm{Kg}$ with three mass center positions of $0.33 \mathrm{~L}, 0.3 \mathrm{~L}$ and $0.27 \mathrm{~L}$ and two different the speeds of 8.05, 11.50 and 14.95. All simulation cases are presented in Table 4. The relevant results of the trim and resistance in all mentioned cases are presented in Table 5.

Table 4. Studied loading conditions

\begin{tabular}{|c|c|c|c|}
\hline $\begin{array}{c}\text { Case } \\
\text { No }\end{array}$ & $\begin{array}{c}\mathbf{M} \\
{[k \boldsymbol{g}]}\end{array}$ & $\begin{array}{c}\mathrm{V} \\
{[\mathrm{m} / \mathrm{s}]}\end{array}$ & $\begin{array}{c}\text { LCG [\% L] } \\
\text { from transom }\end{array}$ \\
\hline 1 & \multirow{9}{*}{76} & \multirow{3}{*}{8.05} & 27 \\
\hline 2 & & & 30 \\
\hline 3 & & & 33 \\
\hline 4 & & \multirow{3}{*}{11.50} & 27 \\
\hline 5 & & & 30 \\
\hline 6 & & & 33 \\
\hline 7 & & \multirow{3}{*}{14.95} & 27 \\
\hline 8 & & & 30 \\
\hline 9 & & & 33 \\
\hline 10 & \multirow{9}{*}{84} & \multirow{3}{*}{8.05} & 27 \\
\hline 11 & & & 30 \\
\hline 12 & & & 33 \\
\hline 13 & & \multirow{3}{*}{11.50} & 27 \\
\hline 14 & & & 30 \\
\hline 15 & & & 33 \\
\hline 16 & & \multirow{3}{*}{14.95} & 27 \\
\hline 17 & & & 30 \\
\hline 18 & & & 33 \\
\hline
\end{tabular}

As it could be seen in Table 5, in some cases, unsteady motions of vessel are highlighted. In these cases, the final state results of resistance and trim are periodic and therefore the upper and lower limits are reported. This unsteady and harmonic behavior of vessel over the calm water shows a "porpoise instability" which is a common phenomenon for real planing boats at high speeds. As a sample, a time history variation of trim angle for the case study \#4 that is a representation of porpoise instability, are shown in Figure 11. As it shows, the body motions didn't converge to a constant value. In contrast, for the stable cases such as the case study \#9, the time variation of trim angle is shown in Figure 12.

Table 5. Results for different loading conditions

\begin{tabular}{cccccc}
\hline \multirow{2}{*}{$\begin{array}{c}\text { Case } \\
\text { No }\end{array}$} & \multicolumn{5}{c}{ Rynamic } \\
\cline { 2 - 6 } & $\begin{array}{c}\text { Behavior } \\
\text { Status }\end{array}$ & $\begin{array}{c}\text { Resistance } \\
{[\boldsymbol{N}]}\end{array}$ & $\begin{array}{c}\text { Trim } \\
{[\mathbf{d e g}]}\end{array}$ & $\begin{array}{c}\mathbf{L c} \\
{[\mathbf{c m}]}\end{array}$ & $\begin{array}{c}\mathbf{L K} \\
{[\mathbf{c m}]}\end{array}$ \\
\hline 1 & porpoise & $125-135$ & $4.2-4.8$ & Variable & Variable \\
\hline 2 & converged & 134.75 & 4.08 & 92.6 & 175.6 \\
\hline 3 & converged & 138.4 & 3.69 & 113 & 188 \\
\hline 4 & porpoise & $135-235$ & $1.6-4.3$ & Variable & Variable \\
\hline 5 & converged & 196.1 & 2.668 & 76 & 186.6 \\
\hline 6 & converged & 206.5 & 2.48 & 88.4 & 193.7 \\
\hline 7 & porpoise & $272-288$ & $2.07-2.2$ & Variable & Variable \\
\hline 8 & converged & 307 & 1.965 & 50 & 191 \\
\hline 9 & converged & 323 & 1.805 & 69 & 196 \\
\hline 10 & porpoise & $128-154$ & $3.8-5.9$ & Variable & Variable \\
\hline 11 & converged & 144.3 & 4.435 & 97.5 & 172 \\
\hline 12 & converged & 149.5 & 4.023 & 111.5 & 184.3 \\
\hline 13 & porpoise & $100-270$ & $1-5.5$ & Variable & Variable \\
\hline 14 & porpoise & $196-206$ & $2.75-3$ & Variable & Variable \\
\hline 15 & converged & 215 & 2.685 & 81.8 & 189.4 \\
\hline 16 & porpoise & $225-310$ & $1.9-2.7$ & Variable & Variable \\
\hline 17 & porpoise & $275-300$ & $2-2.25$ & Variable & Variable \\
\hline 18 & porpoise & $285-315$ & $1.85-2.1$ & Variable & Variable \\
\hline
\end{tabular}

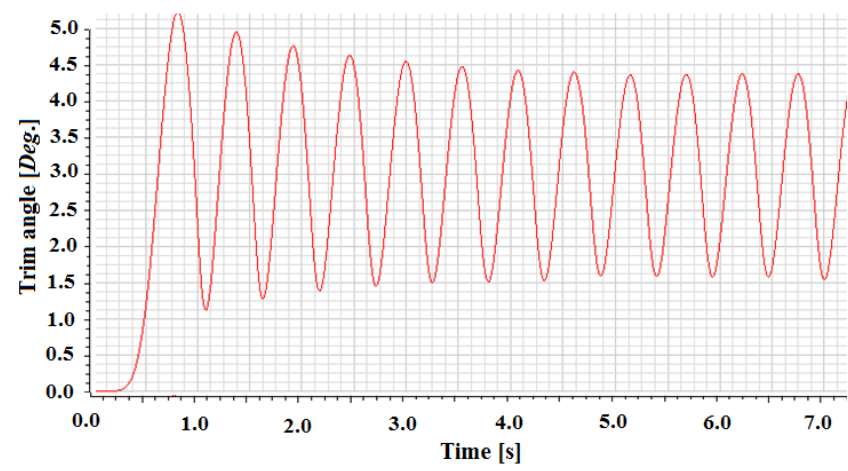

Figure 11. Time variations of trim angle for case study \#4

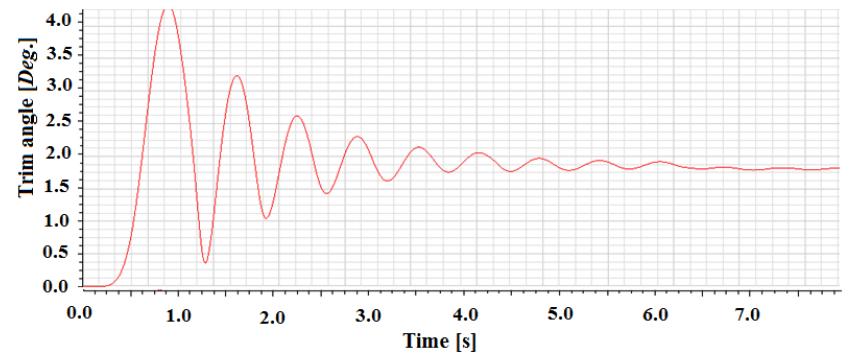

Figure 12. Time variations of trim angle for case study \#9

Comparison of the results of the test cases 1,2 and 3 shows that decreasing the LCG can be a reason for occurring of the "porpoise instability" even for low speeds. It can be confirmed by comparison the results presented for three set test cases of " $4,5,6$ ", "7, 8, 9" and " $10,11,12$ ". Comparison of the result also shows that by increasing the mass values as the LCGs are 
kept same, the probability of occurring of the "porpoise instability" is also increased for higher speeds. This can be seen by comparison between the results of two set of " $7,8,9$ " and " $16,17,18$ ". It should be noted that as the vessel speed increases the hydrodynamic center of pressure, COP, generated at the bottom moved forward. If the COP be located in behind the LCG, the porpoise instability may be occurred.

As some samples, free surface shape and wave pattern around the vessel, pressure distribution pattern and frictional resistance coefficient, $\mathrm{C}_{\mathrm{f}}$, on the bottom of the vessel in different speeds for $76 \mathrm{Kg}$ model and longitudinal center of gravity of $0.33 \mathrm{~L}$ are depicted in Figure 13 to 15.

Figure 13 shows that as the vessel speed increased the width of the wake or disturbed region decreased and the height of generated waves by the vessel also decreased. These are consistent well with real planing boats. It means that by increasing of vessel speed, the interaction between the vessel and water surface reduces due to reduce in the sinkage of the vessel. This is an important characteristic for planing vessels.

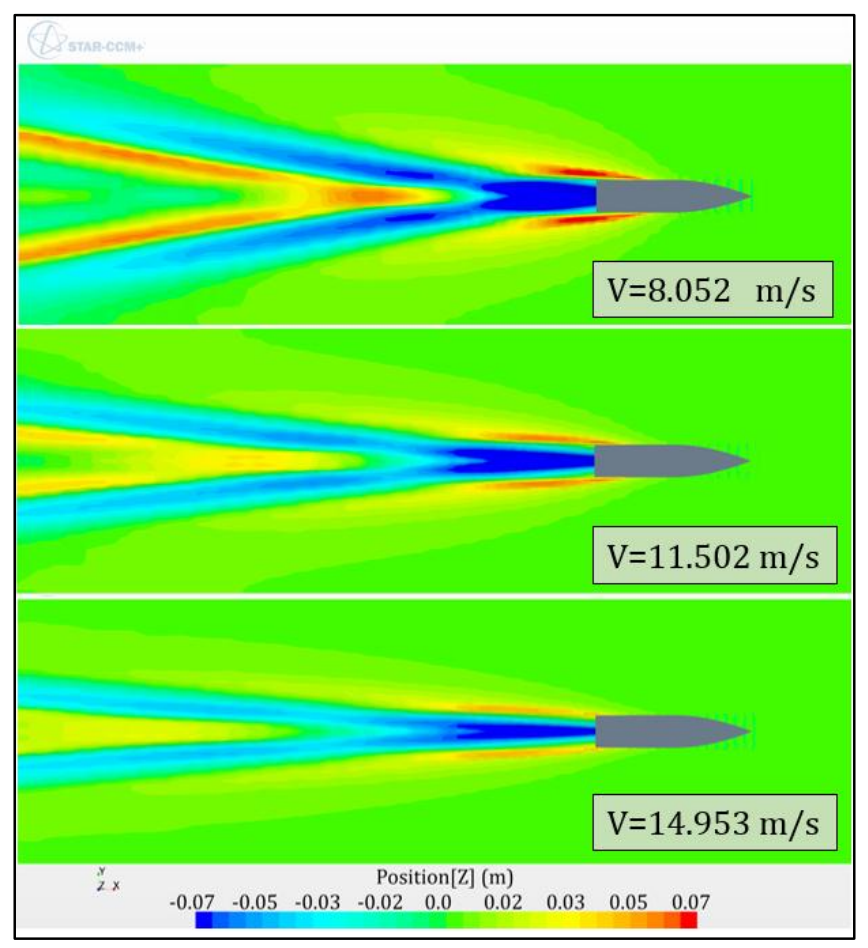

Figure 13. Wave patterns and sea surface effects at different speeds

Figure 14 and 15 indicate that as the vessel speed increased the leading edge of the wetted surface moved forward due to decreasing in trim angle of the vessel. The high pressure region is also extended forward. By extending the high pressure region to fore of the vessel, it may be occurred a situation that the center of pressure set upward the longitudinal center of gravity and cause the "porpoise instability".

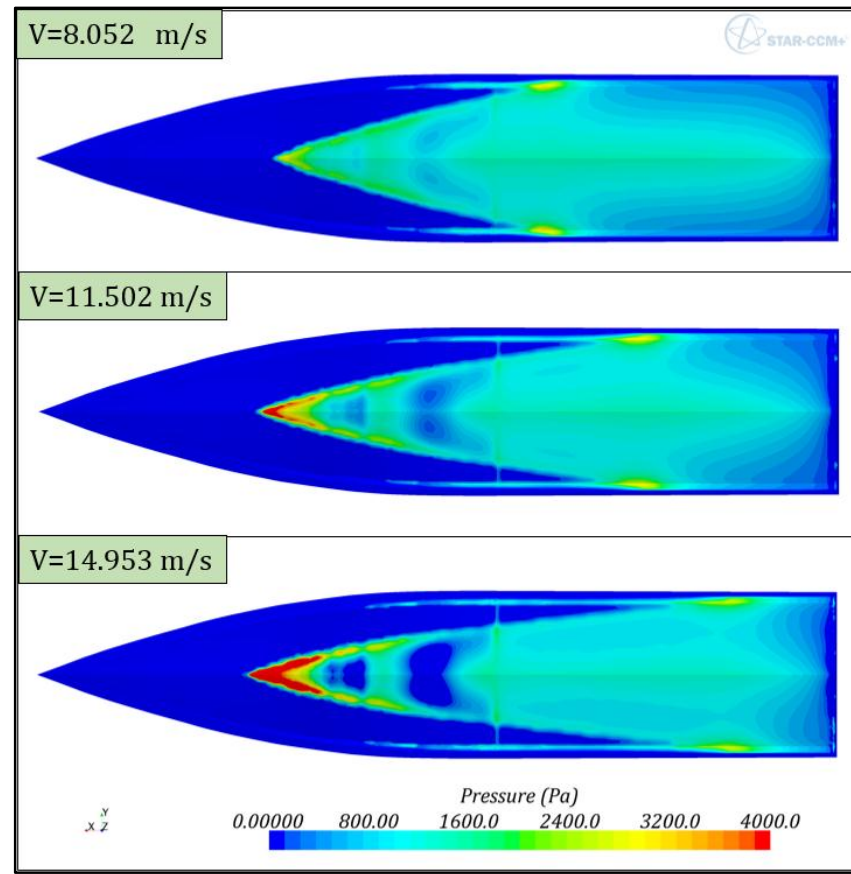

Figure 14. Pressure counter on the bottom of the vessel in different speeds.

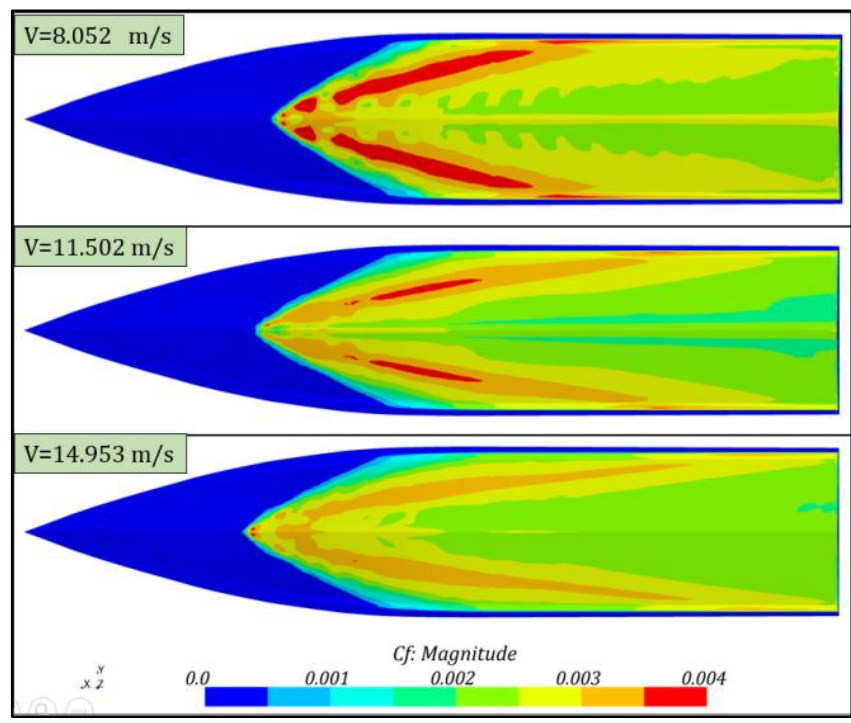

Figure 15. $C_{f}$ variations over the bottom of the vessel

\section{Conclusion}

A numerical and experimental hydrodynamic analysis for a hard-chine planing boat with different loading conditions and speed is presented. Firstly the laboratory tests are carried out in three different conditions of weight, speed and mass center. Then a newly developed moving mesh method, called as Overset, which included within the Star-CCM+ software, is utilized to investigate the hydrodynamics of the vessel for 18 different loading conditions numerically. Comparison of numerical and laboratory results showed a good consistency between them. One of main objective of this research is to obtain such conditions of mass properties and speeds in which the planing vessel didn't experience the longitudinal instability of "porpoising". Hence the effect of longitudinal center of gravity and the weight in 
different speeds on hydrodynamic resistance of the body and trim behavior have analyzed. Results showed as the model weight increased, the resistance and the final trim angle of the vessel also increased. By increasing of the model speed, while other conditions constant kept constant, the resistance increased and the trim decreased. As the position of longitudinal center of gravity moves toward the stern, the trim angel increases and the relevant resistance decreases and the probability of occurring of longitudinal dynamic instability increases. The probability of proposing phenomenon increases with increasing of the model weight

\section{References}

1-Doctors, L. J., (1985), Hydrodynamics of Highspeed Small Craft, University of Michigan, Technical Report.

2-Savitsky, D., Morabito, M., (2010), Surface wave contours associated with the forebody wake of stepped planing hulls, Marine Technology, Vol. 47, No. 1, pp.1-16.

3- Lotfi, P., Ashrafizaadeh, M., Esfahan, R. K., (2015), Numerical investigation of a stepped planing hull in calm water, Ocean Engineering, Vol. 94, pp. 103-110.

4- Clement, E. P., Blount, D. L., (1963), Resistance tests of systematic series of planing hull forms, SNAME Transaction, Vol.71, pp. 491-579.

5- Seo, J., Choi, H. K., Jeong, U. C., Lee, D. K., Rhee, S. H., Jung, C. M., Yoo, J., (2016), Model tests on resistance and seakeeping performance of wavepiercing high-speed vessel with spray rails, International Journal of Naval Architecture and Ocean Engineering, Vol. 8, pp. 442-455.

6- Faltinsen, O. M., (2006), Hydrodynamics of HighSpeed Marine Vehicles, Cambridge University Press, New York, NY 10011-4211, USA.

7- Caponnetto, M., (2001), Practical CFD simulations for planing hulls, Proceedings of Second International Euro Conference on High Performance Marine Vehicles, Hamburg, pp.128-138.

8- Ghassemi, H., Su, Y., (2008), Determining the hydrodynamic forces on a planing hull in steady motion, Journal of Marine Science and Application, Vol.7, pp. 147-156.

9- Brizzolara, S., Serra, F., (2007), Accuracy of CFD codes in the prediction of planing surfaces hydrodynamic characteristics, Second International Conference on Marine Research and Transportation, pp. 147-159.
10- Savitsky, D., (1964), Hydrodynamic design of planing hull, Marine Technology, Vol. 1, No. 1, pp. 71-95.

11- Shuford, C. L., (1958), A Theoretical and Experimental Study of Planing Surfaces Including Effects of Cross Section and Plan Form, NACA report-1355.

12- Hay, A., Leroyer, A., Visonneau, M., (2006), $H$ adaptive Navier-Stokes simulations of free-surface flows around moving bodies, Journal of marine science and technology, Vol. 11, pp. 1-18.

13- Su, Y., Chen, O., Shen, H., Lu, W., (2012), Numerical Simulation of a Planing Vessel at High Speed, Journal of Marine Science and Application, Vol. 11, pp.178-183.

14- Garland, W. R., Maki, K. J., (2012), A numerical study of a two-dimensional stepped planing surface, Journal of Ship Production, Vol. 28, No. 2, pp. 60-72. 15- Makasyeyev, M. V., (2009), Numerical modeling of cavity flow on bottom of a stepped planing hull, Proceedings of the Seventh International Symposium Cavitation.

16- Ghadimi, P., Tavakoli, S., Dashtimanesh, A., Pirooz, A., (2014), Developing a Computer Program for Detailed Study of Planing Hull's Spray Based on Morabito's Approach, Journal of Marine Science and Application, Vol. 13, pp. 402-415.

17- Taunton, D., Hudson, D., Shenoi, R., (2010), Characteristics of a series of high speed hard chine planing hulls-part 1: performance in calm water, International Journal of Small Craft Technology, Vol. 152, pp. 55-75.

18-Wang, S., Su, Y., Zhang, X., Yang, J., (2012), RANSE Simulation of High-speed Planing Craft in Regular Waves, Journal of Marine Science and Application, Vol. 11, pp. 447-452.

19-Ferziger, H. J., Peric, M., (2002), Computational Methods for Fluid Dynamics, third rev. edition, chapter 9.

20- Yousefi, R., Shafaghat, R., \& Shakeri, M. (2013), Hydrodynamic analysis techniques for high-speed planing hulls, Applied Ocean Research, Vol. 42, pp.105-113.

21- Panahi, R., Jahanbakhsh, E., Seif, M. S., (2009),

Towards simulation of $3 D$ nonlinear high-speed vessels motion, Ocean Engineering, Vol. 36, No. 3, pp. 256-265.

22- Sukas, O. F., Kinaci, O. K., Cakici, F., Gokce, M. K. (2017), Hydrodynamic assessment of planing hulls using overset grids.,Applied Ocean Research, Vol. 65, pp. 35-46. 